\title{
Cerebral oxygenation during cardiopulmonary bypass
}

\author{
S P Wardle, C W Yoxall, A M Weindling
}

\begin{abstract}
Cerebral fractional oxygen extraction (FOE) was monitored in 30 children, using near infrared spectroscopy during cardiopulmonary bypass, to investigate the effect of hypothermia and circulatory arrest. One group of children $(n=15)$ underwent profound hypothermia with total circulatory arrest $(n=8)$ or continuous flow $(n=7)$. Another group $(n=15)$, of whom only one had circulatory arrest, underwent mild $(n=6)$ or moderate $(n=$ 9) hypothermia.
\end{abstract}

The mean FOE (SD) before bypass was $0.35(0.12)$ and this correlated negatively with the preoperative arterial oxygen content $(r=-0.58)$. Between the stage of cooling on bypass and cold bypass there was a reduction in FOE in all groups. Between cold bypass and rewarming there was an increase in FOE only in the groups with continuous flow. In the circulatory arrest group, the FOE remained low during rewarming and was significantly lower than that of the continuous flow group. No patients died and none had neurological abnormalities postoperatively.

Apparent changes in oxidised cytochrome oxidase concentration were also monitored using near infrared spectroscopy. There was a fall in cytochrome aa3 on starting cardiopulmonary bypass, but there were no significant differences in the changes in cytochrome aa3 between any stage in any of the patient groups.

Using this non-invasive technique, cooling was shown to reduce cerebral FOE. During rewarming on bypass there was an increase in cerebral FOE only in patients who had had continuous flow bypass. In contrast, the cerebral FOE in those with circulatory arrest remained constant after arrest and during the duration of the study. This may have implications for the timing of hypoxic brain injury. (Arch Dis Child 1998;78:26-32)

Health, Royal

Liverpool Children's

Hospital

S P Wardle

$\mathrm{C}$ W Yoxall

A $M$ Weindling

Correspondence to: Dr S P Wardle,

Department of Child Health,

University of Liverpool,

Neonatal Unit, Liverpool

Women's Hospital,

Crown Street, Liverpool

L8 7SS.

e-mail: s.p.wardle $@$

liverpool.ac.uk

Accepted 22 July 1997

Hypothermia and cardiopulmonary bypass are widely used techniques in paediatric cardiac surgery. Brain injury is a serious cause of morbidity after these procedures and has been reported as occurring in between $1-25 \%$ of paediatric operations. ${ }^{1}$ Hypothermia is used for brain protection mainly because it reduces tissue metabolism and may cause a decrease in free radical activity. ${ }^{2-4}$ It may also be useful in other situations where cerebral protection is needed, for example after birth asphyxia.

It has not previously been possible to measure cerebral venous saturation $\left(\mathrm{SvO}_{2}\right)$ and fractional oxygen extraction (FOE) non-invasively during cardiopulmonary bypass. Previous studies using invasive methodologies have shown changes in cerebral oxygenation during cardiac bypass, ${ }^{5-7}$ the most important being a decrease in oxygen consumption during hypothermia and a fall in cerebral venous saturation during rewarming. Non-invasive studies by near infrared spectroscopy during hypothermia and circulatory arrest of changes in the relative concentrations of the chromophores oxyhaemoglobin and deoxyhaemoglobin and oxidised cytochrome oxidase have relied on estimates of the path length of light to produce continuous recordings of semiquantitative measurements of the concentrations of the chromophores to study trends in the change in oxygenation in the brain..$^{7-12}$ Absolute quantification, however, has not been possible. Absolute measurements of cerebral $\mathrm{SvO}_{2}$ can, however, be made using near infrared spectroscopy, without reference to an optical path length estimation, by causing a brief partial jugular venous occlusion. ${ }^{13}$ This technique has been validated by comparison with invasive measurements of cerebal $\mathrm{SvO}_{2}$ from co-oximetry of blood from the jugular bulb. ${ }^{13}$ Measurements of cerebral $\mathrm{SvO}_{2}$, together with measurements of arterial saturation $\left(\mathrm{SaO}_{2}\right)$ made by pulse oximetry, can be used to calculate the cerebral FOE, a measure of the balance between the oxygen consumption and oxygen delivery.

FOE varies from organ to organ and with levels of activity. Measurements of FOE for the whole body produce a range of approximately 0.15 to 0.33 . That is the body consumes $15 \%$ to $33 \%$ of oxygen transported. ${ }^{14}{ }^{15}$ The heart and brain are likely to have consistently high values of FOE, whereas muscle may have variable levels with higher oxygen extraction during active states.

The purpose of this study was to investigate by a non-invasive method cerebral oxygenation during induced hypothermia. Our primary hypothesis was that cooling for cardiac bypass operations reduced cerebral FOE.

Near infrared spectroscopy may also be able to monitor the redox status of cytochrome oxidase (cytochrome aa3), the terminal enzyme in the respiratory electron transport chain responsible for ATP production within the cell. In hypoxic piglets, reduction of cytochrome aa3 has been shown to correlate with a decrease in brain energy state measured by nuclear magnetic resonance spectroscopy. ${ }^{16}$ 
Monitoring this variable might therefore provide useful information on the intracellular use of oxygen. A secondary hypothesis of this study was that there was a difference in the changes in cerebral FOE and cytochrome aa3 in children subjected to circulatory arrest during hypothermia.

\section{Method}

NEAR INFRARED SPECTROSCOPY

Measurements were made using the Hamamatsu NIRO-500 (Hamamatsu UK). Data were stored in a computer file for analysis offline, using a spreadsheet package (Lotus 1-2-3).

After induction of anaesthesia, the monitoring optodes were positioned on the frontotemporal region of the child's head. One optode was placed centrally on the forehead below the hairline, and the other was positioned temporally as far away as possible, on the forehead and below the hairline. In practice, the interoptode distance was between $4-7 \mathrm{~cm}$, the exact distance depending on the size and shape of the child's head. The optodes were fixed tightly in place using elastic adhesive tape, with the aim of reducing scalp blood flow in the optical field. The monitoring optodes were removed before the patient's transfer to the paediatric intensive care unit.

Using measurements of cerebral $\mathrm{SvO}_{2}$ by near intrared spectroscopy with partial venous occlusion and $\mathrm{SaO}_{2}$ by pulse oximetry, values for the cerebral FOE were calculated: $\mathrm{FOE}=\left(\mathrm{SaO}_{2}-\mathrm{SvO}_{2}\right) / \mathrm{SaO}_{2}$.

These measurements involved minimal disturbance of the subject, and repeated measurements were possible. It was not possible to make measurements of FOE during circulatory arrest, as measurement of FOE by this method requires continuous circulation.

Each measurement of $\mathrm{SvO}_{2}$ involved making five unilateral partial jugular venous occlusions which took approximately 30 seconds. The $\mathrm{SvO}_{2}$ was calculated as the mean of these five measurements. They were made every 10 minutes throughout the operation, most frequently during cooling and rewarming. Measurements of $\mathrm{SaO}_{2}$, arterial blood pressure, and nasal temperature (representing brain temperature) were recorded at the time of each measurement of cerebral $\mathrm{SvO}_{2}$. In addition, the packed cell volume was measured approximately every 30 minutes at each stage of the operation.

At the time of each measurement of cerebral FOE, cytochrome aa 3 data was logged every 0.5 seconds, and these data were averaged over a 60 second period. These measurements were made throughout the operation including during hypothermic circulatory arrest. The differential path length factor was set at that recommended for the neonatal head in children less than 3 months of age, and set for that recommended for the adult head in the other children. ${ }^{17}$

ANAESTHETIC AND BYPASS TECHNIQUE

Hypothermia was graded according to the minimum core temperature achieved during cooling. During paediatric operations at this hospital, children are cooled to target temperatures of $15^{\circ} \mathrm{C}$ (profound hypothermia), 22$24^{\circ} \mathrm{C}$ (moderate hypothermia), or $28^{\circ} \mathrm{C}$ (mild hypothermia), and circulatory arrest is used in selected children according to the surgical requirements.

A central venous catheter was inserted and a femoral artery cannulated for monitoring of systemic arterial pressure. A urinary catheter and nasopharyngeal and oesophageal temperature probes were inserted after induction of anaesthesia and a peripheral tissue oxygen saturation probe was taped in place.

The haemoglobin concentration was measured the day before the operation and the arterial oxygen content $\left(\mathrm{CaO}_{2}\right)$ was calculated using this and the $\mathrm{SaO}_{2}$ at the time of measurement of the cerebral FOE before bypass: $\mathrm{CaO}_{2}=$ (haemoglobin) $\times 1.34 \times \mathrm{SaO}_{2}$, where 1.34 is the quantity of oxygen (ml) carried by $1 \mathrm{~g}$ of haemoglobin, and assumes that the quantity of dissolved oxygen is negligible.

A standard anaesthetic protocol was used for each of the patients and the degree and duration of hypothermia was decided by the surgeon. The hollow fibre D701 oxygenator (Dideco) used for cardiopulmonary bypass was primed with warmed blood and crystalloid. Bypass flow was set initially at $2.41 / \mathrm{min} / \mathrm{m}^{2}$ and this was altered in some patients to suit surgical requirements. The rate of cooling and rewarming was controlled to approximately $1^{\circ} \mathrm{C}$ per minute. During surgical preparation patients were surface cooled by exposure to a $15^{\circ} \mathrm{C}$ ambient operating theatre. The packed cell volume was maintained at $25+/-5 \%$. Intermittent arterial blood gas measurement was used to maintain a constant arterial partial pressure of oxygen $\left(\mathrm{PaO}_{2}\right)$ aided by the use of an inline $\mathrm{PaO}_{2}$ monitor (Polystan). Similarly, a capnograph (Datex Ltd) attached to the gas outlet port of the oxygenator helped to maintain a constant arterial carbon dixoide tension $(5.3+/-0.5 \mathrm{kPa}$, temperature uncorrected, that is, alpha-stat regulation). ${ }^{18}$ Inotropic support was given as required to aid weaning from cardiopulmonary bypass during rewarming.

\section{STUDY DESIGN}

This was an observational study. Thirty children undergoing operations involving hypothermia were studied after informed parental consent. Measurements were made on 30 children. Fifteen children underwent profound hypothermia and eight of these underwent total circulatory arrest; nine children underwent moderate hypothermia of whom one had circulatory arrest. None of the children who had mild hypothermia $(n=6)$ underwent circulatory arrest.

The neurological status of the children was assessed daily during the first seven postoperative days by clinical neurological examination. Abnormal neurological status was defined as focal or generalised abnormal neurological signs, unexpected decreased consciousness that was not attributable to sedative drugs, or seizures. 
Table 1 Descriptive details of patients studied. Variables are shown as medians and ranges

\begin{tabular}{|c|c|c|c|c|c|}
\hline & \multicolumn{2}{|c|}{ Profound hypothermia } & \multicolumn{2}{|c|}{ Moderate hypothermia } & \multirow{2}{*}{$\begin{array}{l}\text { Mild hypothermia } \\
\begin{array}{l}\text { Continuos flow } \\
(n=6)\end{array}\end{array}$} \\
\hline & $\begin{array}{l}\text { Circulatory arrest } \\
(n=8)\end{array}$ & $\begin{array}{l}\text { Continuous flow } \\
(n=7)\end{array}$ & $\begin{array}{l}\text { Circulatory arrest } \\
(n=1)\end{array}$ & $\begin{array}{l}\text { Continuous flow } \\
(n=8)\end{array}$ & \\
\hline Age (months) & $4(1-43)$ & $6(3-97)$ & 42 & $32.5(7-182)$ & $34(13-70)$ \\
\hline Minimum temperature $\left({ }^{\circ} \mathrm{C}\right)$ & $16.5(15-21)$ & $20(19-21)$ & 24 & $24(23-27)$ & $30(29-32)$ \\
\hline \multicolumn{6}{|l|}{ Operation } \\
\hline VSD & 3 & 4 & 0 & 4 & 0 \\
\hline ASD & 0 & 0 & 0 & 2 & 6 \\
\hline Other & 5 & 3 & 1 & 3 & 0 \\
\hline Cyanosis & 3 & 3 & 1 & 2 & 0 \\
\hline Reduced flow rate & - & 3 & - & 3 & 0 \\
\hline
\end{tabular}

$\mathrm{A} / \mathrm{VSD}=$ atrial $/$ ventricular septal defect

The operation was divided into five arbitrary stages: before bypass, cooling on bypass, cold bypass, rewarming on bypass, and after bypass. Before bypass was defined as the period between the first measurement made after the patient was stable after induction of anaesthesia and before bypass flow began. Cooling was the period during which the patient was being actively cooled on cardiopulmonary bypass with full bypass flow. Cold bypass was the period during which the minimum core temperature was reached and during which the temperature did not vary by more than +/$1^{\circ} \mathrm{C}$; during this period some patients were subjected to total circulatory arrest and alterations in bypass flow rate. Rewarming bypass was the period between the start of active rewarming on bypass and cessation of bypass flow. After bypass was the period between cessation of bypass flow and the end of the operation.

STATISTICS

The mean FOE for each patient was determined for each stage. Patients were then considered as groups: cerebral FOE of children with profound hypothermia were compared with those who had mild/moderate hypothermia; the effect of circulatory arrest was compared with that of continuous flow bypass. Changes in mean FOE and median cytochrome aa 3 between stages of the operation in the different groups under consideration were analysed using analysis of variance (ANOVA) and paired $t$ tests for changes in mean FOE at each stage, and ANOVA and Wilcoxon rank sum tests for changes in the cytochrome aa3. Unpaired $t$ tests were used to assess differences in mean FOE among groups.

\section{Results}

Table 1 summarises the patient details in the groups studied. None of the children in the study died or had any postoperative neurological abnormalities detected.

The median (range) number of measurements was 5 (1-18) during each stage of the operation, depending on the length of each stage. Six children did not have FOE measurements taken during cold bypass because it was not possible in the time available, or because

Table 2 Summary of changes in blood pressure, nasal temperature, haemoglobin concentration, cerebral FOE, and oxidised cytochrome oxidase concentration in the different groups. FOE is expressed as mean (SD), other variables are expressed as median (range)

\begin{tabular}{|c|c|c|c|c|c|}
\hline & \multicolumn{2}{|l|}{ Profound hypothermia } & \multicolumn{2}{|c|}{ Moderate hypothermia } & \multirow{2}{*}{$\begin{array}{l}\text { Mild hypothermia } \\
\text { Continuous flow } \\
(n=6)\end{array}$} \\
\hline & $\begin{array}{l}\text { Continuous flow } \\
(n=7)\end{array}$ & $\begin{array}{l}\text { Circulatory arrest } \\
(n=8)\end{array}$ & $\begin{array}{l}\text { Continuous flow } \\
(n=8)\end{array}$ & $\begin{array}{l}\text { Circulatory arrest } \\
(n=1)\end{array}$ & \\
\hline \multicolumn{6}{|l|}{ Cerebral FOE } \\
\hline Before bypass & $0.371(0.18)$ & $0.384(0.09)$ & $0.362(0.15)$ & 0.29 & $0.340(0.05)$ \\
\hline Cooling & $0.412(0.17)$ & $0.400(0.13)$ & $0.368(0.10)$ & 0.44 & $0.440(0.08)$ \\
\hline Cold bypass & $0.350(0.02)$ & $0.415(0.10)$ & $0.367(0.14)$ & 0.25 & $0.390(0.03)$ \\
\hline Rewarming & $0.463(0.10)$ & $0.356(0.08)$ & $0.455(0.09)$ & 0.32 & $0.440(0.08)$ \\
\hline After bypass & $0.417(0.16)$ & $0.353(0.13)$ & $0.388(0.15)$ & 0.42 & $0.380(0.06)$ \\
\hline \multicolumn{6}{|c|}{ Systolic blood pressure $(\mathrm{mm} \mathrm{Hg})$} \\
\hline Before bypass & $89(76-95)$ & $79.5(54-89)$ & $96(85-112)$ & 110 & $85(79-103)$ \\
\hline Cooling & $39(33-102)$ & $47(37-140)$ & $51(36-103)$ & 51 & $61(43-123)$ \\
\hline Cold bypass & $49.5(20-71)$ & $70(66-72)$ & $45(13-86)$ & 33 & $87(80-151)$ \\
\hline Rewarming & $55(46-63)$ & $60(45-118)$ & $66(48-98)$ & 56 & $73(49-134)$ \\
\hline After bypass & $68(64-92)$ & $77(66-97)$ & $98(74-116)$ & 70 & $99(85-108)$ \\
\hline \multicolumn{6}{|c|}{ Haemoglobin $(\mathrm{g} / \mathrm{dl})$} \\
\hline Before bypass & $11.4(10.3-18.7)$ & $12.6(10.3-17.4)$ & $12.9(10.5-14.6)$ & 16.3 & $12.9(11.7-13.4)$ \\
\hline Cooling & $7.5(6.8-13)$ & $8.9(5.6-10.7)$ & $9.3(6.3-11.7)$ & 10.7 & $9.9(8.1-12.2)$ \\
\hline Cold bypass & $10.5(8.9-12)$ & $10(8.6-13.5)$ & $9.8(5.7-11.7)$ & 10.0 & $9.7(8.1-12.2)$ \\
\hline Rewarming & $10.5(8.9-12)$ & $10(8.6-13.5)$ & $9.8(5.7-11.7)$ & 10.0 & $9.7(8.1-12.2)$ \\
\hline After bypass & $11.7(10-12.7)$ & $11.8(10.5-15.9)$ & $10(5.9-11.4)$ & 12.0 & $10.9(8.7-12.2)$ \\
\hline \multicolumn{6}{|c|}{ Nasal temperature $\left({ }^{\circ} \mathrm{C}\right)$} \\
\hline Before bypass & $36.6(35.3-37.0)$ & $36.2(35.3-36.6)$ & $36.3(35.9-37.0)$ & 36.1 & $36.4(35.4-36.7)$ \\
\hline Cooling & $27.0(25.0-31.4)$ & $24.2(21.8-28.0)$ & $30.2(27.0-33.2)$ & 29.3 & $32.1(30.1-33.8)$ \\
\hline Cold bypass & $21.6(20.4-22.5)$ & $17.6(16.3-23.8)$ & $25.9(22.7-26.9)$ & 25.4 & $30.7(30.2-31.7)$ \\
\hline Rewarming & $31.4(28.5-32.4)$ & $29.3(27.4-36.1)$ & $33.1(30.6-35.2)$ & 32.3 & $35.2(33.4-37.9)$ \\
\hline After bypass & $35.5(35.1-37.0)$ & $36.0(35.5-37.4)$ & $36.2(35.0-37.2)$ & 35.6 & $36.4(35.7-37.4)$ \\
\hline \multicolumn{6}{|c|}{$\begin{array}{l}\text { Change in oxidised cytochrome } \\
\text { oxidase }(\mu \mathrm{mol} / \mathrm{l})\end{array}$} \\
\hline Before bypass & 0 & 0 & 0 & 0 & 0 \\
\hline Cooling & $-0.3(-2.1$ to 4.0$)$ & $-1.0(-2.5$ to 1.5$)$ & $-0.3(-0.8$ to 0.2$)$ & -1.1 & $-0.97(-3.1$ to -0.1$)$ \\
\hline Cold bypass & $-0.3(-2.1$ to 5.1$)$ & $-0.8(-2.9$ to 1.9$)$ & $-0.5(-0.8$ to 1.3$)$ & -1.57 & $-2.4(-2.9$ to -0.9$)$ \\
\hline Rewarming & $0.0(-2.5$ to 5.7$)$ & $-1.1(-3.6$ to 2.3$)$ & $-0.1(-0.8$ to 1.1$)$ & -1.96 & $-1.8(-2.9$ to -0.2$)$ \\
\hline After bypass & $0.7(-2.4$ to 1.7$)$ & $0.4(-4.3$ to 3.3$)$ & $-0.2(-0.6$ to 1.5$)$ & -1.44 & $-1.2(-2.7$ to 0.7$)$ \\
\hline
\end{tabular}




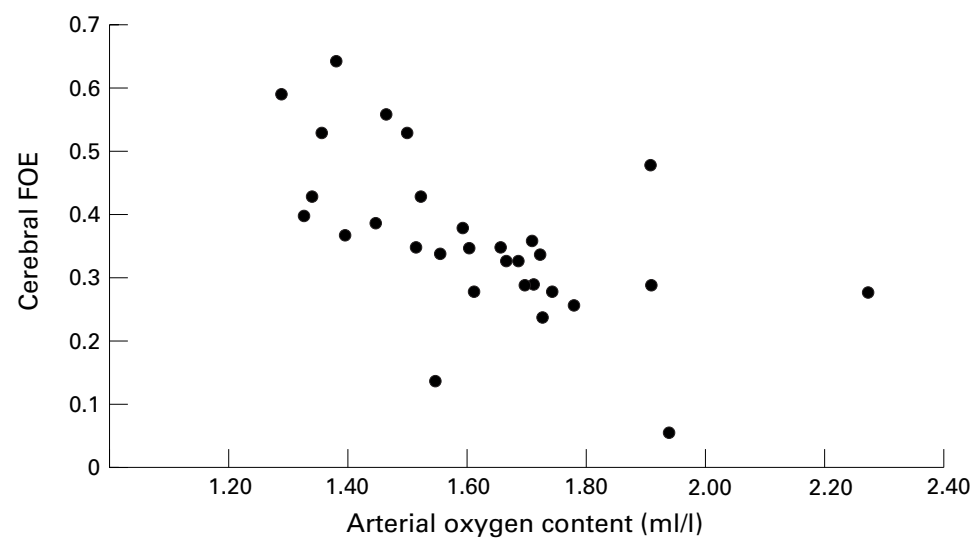

Figure 1 Relation between preoperative arterial oxygen content and mean cerebral FOE before cardiac bypass $(n=30, r=-0.58, p=0.001)$.

circulatory arrest was started as soon as the minimum temperature was reached.

The bypass flow rate was altered in six children during cold bypass other than for episodes of circulatory arrest. Bypass flow was reduced to half for a median time of 16 minutes (range four to 60 minutes). Only one patient was reduced to quarter flow for a 15 minute period. There was no relation between flow rate and FOE within individuals $(r=0.09, \mathrm{p}=0.31)$ during cold bypass and there was no difference in mean FOE at any stage of the operation among those with reduced flow rate and those with full flow rate $(\mathrm{p}=85, \mathrm{p}=0.62$ for cold bypass and rewarming respectively). Table 2 summarises the changes in blood pressure, temperature, and haemoglobin concentration in the different groups.

CEREBRAL FOE

Before cardiac bypass, the mean FOE (SD) was $0.360(0.12)$. The mean FOE (SD) at the end of the operation was $0.384(0.12)$, and this was not significantly different to the before bypass value ( $\mathrm{n}=30, \mathrm{p}=0.23$ ).

The mean (SD) preoperative haemoglobin concentration was $13.1(2.3) \mathrm{g} / \mathrm{dl}$. The mean FOE before bypass correlated negatively with the preoperative haemoglobin concentration (n $=30, r=-0.637, \mathrm{p}<0.01)$ and with the arterial oxygen content $(\mathrm{n}=30, r=-0.58, \mathrm{p}=$ 0.001 ) (fig 1). The temperature and systolic blood pressure showed little variation during this stage as the patients were stable and anaesthetised and not being actively cooled.

During the subsequent stages, nine $(30 \%)$ of the patients had at least one FOE measurement operation above the 95th centile $(0.60)$ for the preoperative normal range. Six children had an FOE above the 95th centile on more than one occasion: in five $(55.6 \%)$, these episodes occurred during rewarming, and in five $(55.6 \%)$, they occurred during the period after bypass. Since measurements were made intermittently, it was not possible to determine exactly how long these episodes lasted. In eight cases the total period during which FOE was increased above the 95 th centile was less than 10 minutes, but in one case there was a 20 minute period where the cerebral FOE was persistently above 0.60 . This was during the rewarming period in a child subjected to profound hypothermia with continuous flow bypass, and whose short term outcome was normal. None of the children had any signs of neurological injury.

EFFECTS OF PROFOUND HYPOTHERMIA COMPARED WITH MILD/MODERATE HYPOTHERMIA

The results from children who underwent mild or moderate hypothermia were considered together because the changes in these two groups were similar. There were 15 children in the profound hypothermia group and 15 children in the mild/moderate hypothermia group. Table 3 shows the mean FOE during each stage of the bypass procedure. There were no significant differences between these two groups at any stage of the operation.

\section{EFFECTS OF CIRCULATORY ARREST COMPARED} WITH CONTINUOUS FLOW BYPASS

Eight of the children in the profound hypothermia group, and one in the moderate hypothermia group, were subjected to total circulatory arrest. They were compared with the 21 other children studied where continuous flow bypass was used. The median (range) arrest time was 32 (14-64) minutes. In the circulatory arrest group, the mean FOE (SD) during cold bypass before the onset of circulatory arrest was 0.392 (0.11) and there was no significant change in mean FOE (SD) on rewarming $(\mathrm{n}=7, \mathrm{p}=$ 0.22 ). The mean FOE (SD) in the continuous flow group during cold bypass was 0.362 (0.16) and in this group there was a significant increase during rewarming $(\mathrm{n}=17, \mathrm{p}=0.013$, see fig 2). The mean FOE (SD) during rewarming of children who underwent circulatory arrest was $0.352(0.08)$, and this was significantly lower $(\mathrm{p}=0.006)$ for those cases in which there was no circulatory arrest $(0.452$ (0.09), fig 2). This was not related to the temperature when circulatory arrest occurred or the duration of cold bypass. In the after bypass period the mean FOE (SD) of the continuous flow group was $0.395(0.13)$; this was a significant decrease $(n=21, p=0.03)$. By contrast the FOE of the circulatory arrest group remained low after bypass at $0.360(0.12)$ and this was not significantly different than the

Table 3 Results of analysis of changes in mean FOE (SE) between each stage of the operation for the different temperature groups

\begin{tabular}{llll}
\hline & All patients $(n=30)$ & Profound hypothermia $(n=15)$ & Mild/moderate hypothermia $(n=15)$ \\
\hline Before bypass & $0.362(0.023) \mathrm{p}=0.13$ & $0.378(0.035) \mathrm{p}=0.52$ & $0.347(0.030) \mathrm{p}=0.12$ \\
Cooling & $0.404(0.022) \mathrm{p}=0.01$ & $0.405(0.037) \mathrm{p}=0.01$ & $0.402(0.024) \mathrm{p}=0.25$ \\
Cold bypass & $0.371(0.029) \mathrm{p}=0.06$ & $0.380(0.044) \mathrm{p}=0.50$ & $0.360(0.038) \mathrm{p}=0.003$ \\
Rewarming & $0.428(0.020) \mathrm{p}=0.10$ & $0.414(0.029) \mathrm{p}=0.53$ & $0.443(0.026) \mathrm{p}=0.06$ \\
After bypass & $0.384(0.023$ & $0.383(0.036)$ & $0.386(0.029)$ \\
\hline
\end{tabular}

$\mathrm{p}$ Values refer to the results of paired $t$ tests between consecutive stages for each group. 


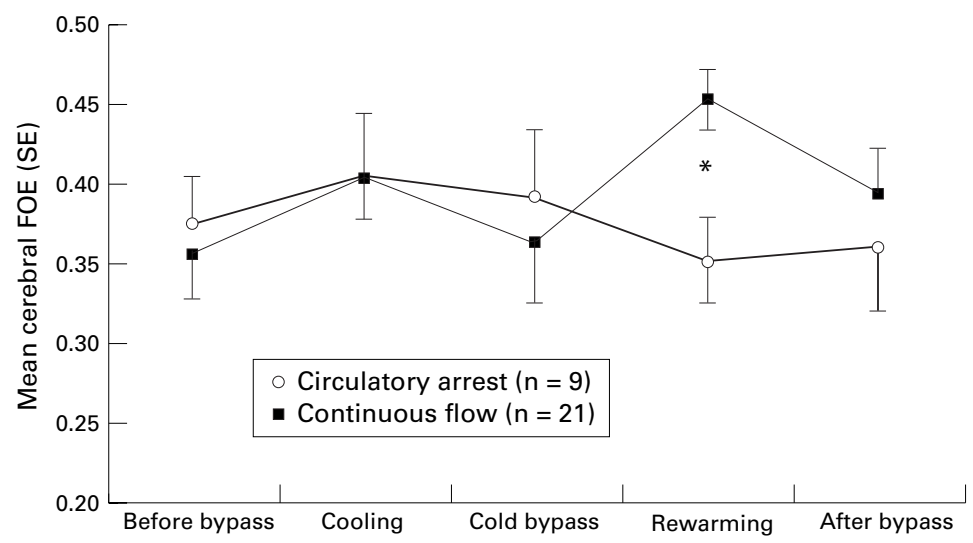

Figure 2 Changes in cerebral FOE (mean +/- standard error) in circulatory arrest and continuous flow groups during the five stages of bypass operation. ${ }^{\star} p=0.006$ unpaired test between circulatory arrest and continuous flow groups. The other stages showed no sifnificant difference between the groups. See text for further comparisons.

FOE during rewarming $(\mathrm{n}=9, \mathrm{p}=0.86$, fig 2$)$. When comparing the two groups there was no significant difference in cerebral FOE in the period after bypass $(\mathrm{p}=0.5)$.

\section{CHANGES IN CYANOSED AND NON-CYANOSED} PATIENTS

There were eight patients who were cyanosed preoperatively $\left(\mathrm{SaO}_{2}<90 \%\right)$. The $\mathrm{FOE}$ of these patients was significantly lower than that of patients who were not cyanosed. Their haemoglobin concentrations were also significantly higher (table 4). When these patients were started on bypass the oxygen saturation increased significantly and there was a significant rise in FOE (table 4). In the patients who were not cyanosed there was no significant change in FOE at the start of bypass compared with the level before bypass. On bypass, the FOE of the patients with cyanotic heart disease $(0.388(0.16))$ was similar to those who were not $(0.410(0.10), p=0.67)$. Table 4 shows the changes in haemoglobin concentration, $\mathrm{SaO}_{2}$, mean FOE in cyanosed and non-cyanosed children.

CYTOCHROME aa3

In the whole group, there was a significant fall in cytochrome aa3 from before bypass to cooling. The median change (interquartile range, IQR) was $-0.66 \mu \mathrm{mol} / 1 \quad(-1.08$ to -0.20$)$ $(\mathrm{n}=30, \mathrm{p}=0.03)$. There was no significant change between the other stages. For each individual there was no significant relation

Table 4 Haemoglobin concentration (mean (SD)), $\mathrm{SaO}_{2}$, (median (IQR)), FOE (mean $(S D)$ ), and arterial oxygen content (mean (SD)) in cyanosed and non-cyanosed patients at the start of bypass

\begin{tabular}{|c|c|c|c|}
\hline & $\begin{array}{l}\text { Before bypass } \\
(n=8)\end{array}$ & $\begin{array}{l}\text { Bypass } \\
(n=22)\end{array}$ & \\
\hline \multicolumn{4}{|l|}{ Haemoglobin $(\mathrm{g} / \mathrm{dl})$} \\
\hline Cyanosed & $16.0(1.9)$ & $10.1(1.6)$ & $\mathrm{p}=0.01^{\star}$ \\
\hline Non-cyanosed & $12.0(1.2)$ & $8.8(1.9)$ & $\mathrm{p}=<0.01^{\star}$ \\
\hline \multicolumn{4}{|l|}{$\mathrm{SaO}_{2}(\%)$} \\
\hline Cyanosed & $87(75-88)$ & $98(98-99)$ & $\mathrm{p}=<0.001 \dagger$ \\
\hline Non-cyanosed & $98(97-98)$ & $100(99-100)$ & $\mathrm{p}=<0.001 \dagger$ \\
\hline \multicolumn{4}{|l|}{ Cerebral FOE } \\
\hline Cyanosed & $0.248(0.10)$ & $0.388(0.16)$ & $\mathrm{p}=0.001^{\star}$ \\
\hline Non-cyanosed & $0.404(0.11)$ & $0.410(0.10)$ & $\mathrm{p}=0.67^{\star}$ \\
\hline \multicolumn{4}{|c|}{ Arterial oxygen content $(\mathrm{ml} / \mathrm{l})$} \\
\hline Cyanosed & $1.8(2.5)$ & $1.4(2.1)$ & $\mathrm{p}=0.002^{\star}$ \\
\hline Non-cyanosed & $1.6(1.7)$ & $1.2(2.5)$ & $\mathrm{p}<0.001^{\star}$ \\
\hline
\end{tabular}

^ Refers to paired $t$ tests. $†$ Refers to Wilcoxon's rank sum tests. between the cerebral FOE and change in cytochrome aa3 $(r=0.05, \mathrm{p}=0.25)$. The change in median cytochrome aa3 (IQR) between the before bypass and after bypass stages was 0.59 umol/1 $(0.16$ to 1.44$)$. This change was not statistically significant $(\mathrm{p}=$ $0.74)$.

At the start of bypass, there was a significant decrease in cytochrome aa 3 in those who were not cyanosed ( $\mathrm{p}=0.001, \mathrm{n}=22)$, but no significant change in those who were cyanosed $(\mathrm{p}=0.5, \mathrm{n}=8)$ (table 4$)$. Table 4 summarises the changes in oxidised cytochrome oxidase concentration.

\section{Discussion}

We have shown that during rewarming after cardiac bypass, the cerebral FOE of children who underwent profound hypothermic circulatory arrest remained low. This was in contrast with the results from patients who underwent profound hypothermia and continuous flow in whom cerebral FOE rose significantly. There are two possible explanations. One is that profound hypothermic circulatory arrest induced a decrease in cerebral metabolic rate which persisted in spite of rewarming. ${ }^{7}$ This observation is in line with those from studies using a piglet model of profound hypothermic circulatory arrest: cerebral metabolism was still depressed at 45 minutes of reperfusion but returned to normal only after three hours of reperfusion. ${ }^{19}$ Another possibility is that cerebral cellular function may have been altered in the course of circulatory arrest with inefficient oxygen extraction and a low observed FOE. In this situation, cerebral lactate production would be expected to rise, and this has been shown by van der Linden et al who suggested that global ischaemia during circulatory arrest impeded optimal aerobic glucose metabolism. ${ }^{20}$

None of the children in this study developed neurological problems, and so presumably none exceeded the 'safe' range for cerebral FOE either in terms of duration or absolute value. This was in spite of the fact that an increase above the 95th centile for FOE was seen in more than a quarter of the patients studied. This observation is in line with other studies which studied changes in Svo2 invasively. These studies also reported frequent episodes of "cerebral desaturation" during bypass and found that these episodes were not associated with postoperative neurological impairment. ${ }^{21}{ }^{22}$ However, one study by Croughwell et al related low concentrations of $\mathrm{SvO}_{2}$ measured during cardiac surgery in adults with an impaired postoperative cognitive performance suggesting that global hypoperfusion may have been a cause of this problem after surgery. ${ }^{2}$

The cerebral FOE before bypass was strongly related to the preoperative arterial oxygen content. During this stage of the operation, the patient was relatively stable without fluctuations in cardiac output, blood gases, blood volume, or temperature, so that other factors affecting oxygen delivery were relatively constant. All were unconscious due to anaes- 
thesia, so presumably cerebral oxygen demands were also relatively constant.

In patients in whom continuous flow bypass was used, a significant rise in FOE occurred during rewarming on bypass. This suggested that there had been a change in the balance between supply and consumption of oxygen, either because the cerebral metabolic rate for oxygen had increased at this stage or oxygen delivery had fallen. This stage is therefore likely to be the time when the balance between oxygen delivery and consumption could become compromised in those with continuous flow and therefore when patients may be most vulnerable to hypoxic brain injury.

Considering all 30 patients, FOE decreased between the stage of cooling and cold bypass. Not all patients who underwent mild/moderate hypothermia showed a decrease in FOE between cooling and cold bypass. The decrease in FOE was only significant in those subjected to profound hypothermia. $\mathrm{SaO}_{2}$ did not change during bypass, and the decrease in FOE was due to an increase in $\mathrm{SvO}_{2}$. Other studies which have measured $\mathrm{SvO}_{2}$ by invasive methods have also shown an increase during cooling..$^{5-7} \mathrm{~A}$ drop in temperature was the only major physiological change which occurred between these stages. It therefore seems reasonable to assume that the observed decrease in FOE was due to hypothermia and was caused by an increase in $\mathrm{SvO}_{2}$, which is likely to be as a result of a fall in cerebral oxygen consumption.

In patients who had cyanotic heart disease, there was a significant rise in FOE when bypass was started, but there was no observed change in FOE in patients who were not cyanosed. The explanation for this difference is likely to be due to the interaction of physiological changes which occur when bypass starts. The oxygen saturation increases as blood oxygenation is taken over by the bypass machine, but there is also haemodilution in the bypass circuit. In addition, as the temperature falls, metabolic rate also falls and oxygen demand would be expected to decrease. The direction of change in FOE will reflect the balance of these processes.

Because cytochrome aa 3 changes are difficult to validate and may be affected by changes in brain temperature and cerebral water content during the course of measurement, the significance and validity of our observations of changes in cytochrome aa3 are not known. Because of the variation in path length among individuals, comparisons of cytochrome aa 3 among groups of patients were not possible. No significant difference in cytochrome aa3 was shown during rewarming in those undergoing circulatory arrest in our study despite the difference in FOE, and no change in cytochrome aa 3 was seen during arrest. Measurements of the relative concen tration of cytochrome aa3 did not seem to relate to cerebral FOE. Despite the limitations referred to above, changes recorded by various near infrared spectroscopy instruments have been reported elsewhere, and development of devices that are able to do this are considered a high priority by some authors. ${ }^{24}$
One objective of this study was to discover whether this non-invasive methodology would be suitable for the study of infants undergoing hypothermia for brain protection in other clinical situations. Hypothermia was associated with a decrease in cerebral FOE and differences were shown during rewarming in patients who underwent circulatory arrest compared with those who had continuous flow bypass. The significance of extreme values of FOE, however, remains to be established and requires further study. The measured normal ranges of FOE using near infrared spectroscopy are wide, making interpretation of individual results difficult, but further study should help to clarify what is a safe range for cerebral FOE in different clinical settings.

We would like to thank Mr R Franks, Mr M Pozzi, Dr P Booker, Dr R Thornington, and Dr B Michalska for their help and permission to study their patients. Financial support was provided by the Newborn Appeal and the Alder Hey Research and Development Fund.

1 Ferry PC. Neurologic sequelae of open heart surgery in children. Am ₹ Dis Child 1990;144:369-73.

2 Bigelow WG, Lindsay WK, Harrison RC, et al. Oxygen transport and utilisation in dogs at low body temperatures. Am f Physiol 1950;160:125.

3 Phoon CK. Deep hypothermic circulatory arrest during cardiac surgery: effects on cerebral blood flow and cerebral oxygenation in children. Am Heart 7 1993;125:1739-48.

4 Greeley WJ, Ungerleider RN, Kern FH, et al. Effects of cardiopulmonary bypass on cerebral blood flow in neonates, infants and children. Circulation 1989;80(suppl I):1-209.

5 van der Linden J, Priddy R, Ekroth R, et al. Cerebral perfusion and metabolism during profound hypothermia in perfusion and metabolism during profound hypotherm
children. F Thorac Cardiovasc Surg 1991;102:103-14.

children. F Thorac Cardiovasc Surg 1991;102:103-14.
6 Andrews PJD, Colquhoun AD. Detection of cerebral Andrews PJD, Colquhoun AD. Detection of cerebral
hypoperfusion during cardiopulmonary bypass. Anaesthesia 1994;49:949-53.

7 Greeley WJ, Bracey VA, Ungerleider RM, et al. Recovery of cerebral metabolism and mitochondrial oxidation state is delayed after hypothermic circulatory arrest. Circulation 1991;84(suppl III):400-6.

8 Skov L, Greisen G. Apparent cytochrome aa3 reduction during cardiopulmonary bypass in hypoxaemic children with congenital heart disease. A critical analysis of in vivo near-infrared spectrophotometric data. Physiol Meas 1994; 15:447-57.

9 du Plessis AJ, Newburger J, Jonas RA, et al. Cerebral oxygen supply and utilisation during infant cardiac surgery. Ann Neurol 1995;37:488-97.

10 Kurth CD, Steven JM, Nicolson SC. Cerebral oxygenation during pediatric cardiac surgery using deep hypothermic during pediatric cardiac surgery using deep hyp

11 Kurth CD, Steven JM, Nicolson SC, et al. Kinetics of cerebral deoxygenation during deep hypothermic circulatory arrest in neonates. Anaesthesiology 1992;77:656-61.

12 Daubeney PE, Pilkington SN, Janke E, et al. Cerebral oxygenation measured by near-infrared spectroscopy: comparison with jugular bulb oximetry. Ann. Thorac Surg 1996; 61:930-4.

13 Yoxall CW, Weindling AM, Dawani, NH, et al. Measurement of cerebral venous oxyhemoglobin saturation in children by near-infrared spectroscopy and partial jugular venous occlusion. Pediatr Res 1995;38:319-23.

14 Levy PS, Chavez RP, Crystal GJ, et al. Oxygen extraction ratio: a valid indicator of transfusion need in limited coronary reserve. F Trauma 1992;32:769-73.

15 Lister G, Walter TK, Versmold HT, et al. Oxygen delivery in lambs: cardiovascular and hematological development. $\mathrm{Am}$ lambs: cardiovascular and he

16 Tsuji M, Naruse H, Volpe J, et al. Reduction of cytochrome aa3 measured by near-infrared spectroscopy predicts cerebral energy loss in hypoxic piglets. Pediatr Res 1995;37: 253-9.

17 Van der Zee P, Cope M, Arridge SR, et al. Experimentally measured optical path-lengths for the adult head, calf and forearm and the head of the newborn infant as a function of interoptode spacing. Adv Exp Med Biol 1992;316:143-53.

18 Bove EL, West HL, Pashanik AM. Hypothermic cardiopulmonary bypass: a compoarison between alpha and $\mathrm{pH}$ stat regulation in the dog. $\mathcal{F}$ Surg Res 1987;42:66-73.

19 Kawata H, Fackler JC, Aoki M, et al. Recovery of cerebral blood flow and energy state in piglets after hypothermic circulatory arrest versus recovery after low-flow bypass. $\mathcal{F}$ Thorac Cardiovasc Surg 1993;106:671-85.

20 Van der Linden J, Astudillo R, Ekroth R, et al. Cerebral lactate release after circulatory arrest but not after low flow in pediatric heart operations. Ann Thorac Surg 1993;56:1485-9. 
21 Croughwell ND, Frasco P, Blumenthal JA, et al. Warming during cardiopulmonary bypass is associated with jugular during cardiopulmonary bypass is associated with jug
bulb desaturation. Ann Thorac Surg 1992;53:827-32.

22 Nakajima T, Kuro M, Hayashi Y, et al. Clinical evaluation of cerebral oxygen balance during cardiopulmonary bypass: on-line continuous monitoring of jugular venous oxyhemoglobin saturation. Anesth Analg 1992;74:630-5.
23 Croughwell ND, Newman MF, Blumenthal JA, et al. Jugular bulb saturation and cognitive dysfunction after cardiopulmonary bypass. Ann Thorac Surg 1994;58: 1702-8.

24 Jonas RA. Cerebral oxygenation during cardiopulmonary bypass in children [commentary]. $\mathcal{F}$ Thorac Cardiovasc Surg 1997;113:78-9.

\section{Succinic semialdehyde dehydrogenase deficiency}

My patient was the daughter of Pakistani parents. She presented with typical features of subacute sclerosing panenecephalitis (SSPE) and the diagnosis was confirmed by a high cerebrospinal fluid measles antibody titre. She had had mild to moderate learning difficulties before the onset of SSPE and a younger brother presented later with developmental slowness and was shown to have succinic semialdehyde dehydrogenase (SSADH) deficiency. Testing of the girl at that time showed that she also had SSADH deficiency as well as SSPE.

A report from several centres in the USA and north west Europe (K Michael Gibson and colleagues, Pediatrics 1997;99:567-74) has added 23 patients with SSADH deficiency to the previously reported total of about 40 . Only seven of the 23 were of American-European or western European origin; four were Turkish, three Indian, two Korean, two Lebanese, and one each Syrian, Saudi, Pakistani, Chinese, and Greenland Inuit. Motor, intellectual, or language delay and hypotonia were each present in about three quarters of the patients. Eleven patients were thought to have had seizures but they were a mixed bag of seizure types often non-recurrent and in several cases dubious. Only in three Indian siblings did epilepsy represent a major problem. Ataxia, behaviour problems, and hyperactivity each affected $30 \%$ of patients.

SSADH deficiency affects GABA (gamma aminobutyric acid) metabolism with accumulation of 4-hydroxybutyric acid. Treatment with vigabatrin has been suggested but it appeared beneficial in only $35 \%$ in this series. High doses of vigabatrin seemed harmful in one patient who responded well to lower dosage.

The diagnosis depends on urine organic acid analysis showing 4-hydroxybutyric aciduria. This group suggests doing such analysis for any patient presenting with two or more of the four main features-intellectual, motor, or language delay, and unexplained hypotonia.

ARCHIVIST 